NASA Technical Memorandum 4324

\title{
A Simulation Evaluation of a Four-Engine Jet Transport Using Engine Thrust Modulation for Flightpath Control
}

Glenn B. Gilyard, Joseph L. Conley, Jeanette Le, and Frank W. Burcham, Jr.

Dryden Flight Research Facility

Edwards, California

\section{N/SA}

National Aeronautics and

Space Administration

Office of Management

Scientific and Technical

Information Program 



\title{
A SIMULATION EVALUATION OF A FOUR-ENGINE JET TRANSPORT USING ENGINE THRUST MODULATION FOR FLIGHTPATH CONTROL
}

\author{
Glenn B. Gilyard * \\ Joseph L. Conley* \\ Jeanette Le* \\ Frank W. Burcham, Jr. ** \\ NASA Dryden Flight Research Facility \\ Edwards, California
}

\begin{abstract}
The use of throttle control laws to provide adequate flying qualities for flightpath control in the event of a total loss of conventional flight control surface use was evaluated. The results are based on a simulation evaluation by transport research pilots of a B-720 transport with visual display. Throttle augmentation control laws can provide flightpath control capable of landing a transport-type aircraft with up to moderate levels of turbulence. The throttle augmentation mode dramatically improves the pilots' ability to control flightpath for the approach and landing flight condition using only throttle modulation. For light turbulence, the average Cooper-Harper pilot rating improved from unacceptable to acceptable (a pilot rating improvement of 4.5 ) in going from manual to augmented control. The low frequency response characteristics of the engines require a considerably different piloting technique. The various techniques used by the pilots resulted in considerable scatter in the data. Many pilots readily adapted to a good piloting technique while some had difficulty. The research demonstrates a new and viable approach to providing an independent means of redundancy or increasing the redundancy capability of transport aircraft flightpath control.
\end{abstract}

\section{Nomenclature}

\begin{tabular}{|c|c|}
\hline ALS & automatic landing system \\
\hline$C_{\ell_{\beta}}$ & nondimensional dihedral effect derivative \\
\hline c.g. & center of gravity \\
\hline FAA & Federal Aviation Administration \\
\hline $\mathrm{PD}$ & proportional and derivative control \\
\hline PID & proportional, integral, and derivative control \\
\hline PR & pilot rating \\
\hline
\end{tabular}

$\begin{array}{ll}p & \text { roll rate, } \mathrm{deg} / \mathrm{sec} \\ q & \text { pitch rate, } \mathrm{deg} / \mathrm{sec} \\ r & \text { yaw rate, } \mathrm{deg} / \mathrm{sec} \\ u, v, w & \text { velocity components, } \mathrm{ft} / \mathrm{sec} \\ \beta & \text { angle-of-sideslip, } \mathrm{deg} \\ \gamma & \text { flightpath angle, deg } \\ \varphi & \text { bank angle, deg }\end{array}$

Prefix

$\Delta$

perturbation

\section{Introduction}

Flight control systems are one of the most critical systems on an aircraft. Current generation aircraft rely on multiple, independent control systems so that any single failure will not disable more than one system, thus leaving the aircraft with satisfactory flight control capability. Despite these design objectives, rare failures have occurred where aerodynamic surface control effectiveness has been significantly impaired or completely lost. This can result from impairment and failures in the electrical, hydraulic, and hardware systems. Such problems can be the result of internal aircraft system failures, external damage such as bird strikes, or, in the case of military aircraft, combat damage.

Significant flight control failures have occurred on two occasions where the hydraulic lines of all systems were severed with subsequent loss of all associated flight control capability. ${ }^{1,2}$ In both instances, major structural damage occurred in the vertical tail area, resulting in damage to all of the independent hydraulic systems. In one case, a bulkhead ruptured on a B-747 aircraft, ${ }^{1}$ leaving only 4 survivors out of 524 passengers. In the other case, an aft fuselage-mounted engine on a DC-10 aircraft suffered major failure with hardware being expelled through the engine casing. A landing was attempted at an airfield using only throttles to control the flightpath, resulting in a high-speed, violent landing. ${ }^{2}$ Although there were casualties, most of the passengers and crew did survive. 
In both the B-747 and DC-10 incidents, the cockpit crew was able to exercise some minimal control of flightpath with manual manipulation of the individual throttles. The difficultly of controlling the longitudinal and lateraldirectional modes satisfactorily with manual throttle motion and no prior experience cannot be overstated. However, these incidences show that throttle-only control may provide minimally satisfactory controllability for the approach and landing task if full advantage can be taken of the control power available.

To better understand aspects associated with controlling aircraft flightpath with throttle modulation in emergency situations, the NASA Dryden Flight Research Facility has undertaken a modest, dual-objective research effort. The first objective is directed at assessing throttle-only fightpath control for a wide range of aircraft including general aviation, transport, and fighters. These evaluations consisted of both flight and simulation studies. ${ }^{3}$ The results show that many aircraft have sufficient control power. If used in an augmented or automatic system, crude approach and landings can be made.

A second objective, the subject of this paper, involved conducting a research feasibility study directed at quantifying the major throttle-only control issues. Cruise and landing tasks were explored using manual, augmented, and automatic throttle-only flightpath control. This study was based on a B-720 early generation jet transport suitable for illustrating and demonstrating the issues involved.

This paper includes the design of augmented control laws using throttle-only control capability. Evaluations of manual and augmented flightpath control for both cruise and landing flight conditions were conducted by transport research pilots. The evaluation tasks are quantified by pilot ratings based on the Cooper-Harper scale ${ }^{4}$ and actual touchdown performance. An automatic landing system was also developed and explored.

\section{Simulated Test Aircraft}

The B-720 model was selected because a high fidelity fixed-base simulation of the aircraft was available based on an earlier joint NASA/FAA flight program. ${ }^{5}$ The simulation includes a visual display of Edwards Air Force Base and all its primary runways, making it suitable for cruise as well as approach and landing flight tasks necessary for aircraft handling quality evaluations.

The B-720 aircraft is a first-generation commercial jet transport and is representative of low-wing aircraft of that generation. It was designed to cruise in excess of Mach 0.80 at altitudes above $30,000 \mathrm{ft}$. The aircraft has an empty weight of approximately $98,000 \mathrm{lb}$ and a maximum gross weight of approximately $200,000 \mathrm{lb}$. A photograph and three-view of the aircraft is shown in Fig. 1.
The primary flight controls are ailerons, elevator, and rudder. Normal pitch trim is provided by a motor-driven, variable incidence stabilizer. The flap deflection range is $0^{\circ}$ to $50^{\circ}$, with the normal deflection for landing at $30^{\circ}$ with an approach speed of 145 knots.

Propulsion for the B-720 aircraft is provided by four JT3C-7 turbojet engines rated at 12,500 -lb thrust. The horizontal displacements of the inboard and outboard engines on the B-720 aircraft from the centerline are 27.2 and $46.1 \mathrm{ft}$, respectively. The vertical displacements of the inboard and outboard engines are 4.1 and $1.7 \mathrm{ft}$ below the center of gravity (c.g.), respectively. Symmetric throttle application affects longitudinal control primarily through speed stability effects and to a lesser degree through the pitching moment arm effects. Figure 2 is a throttle response time history showing the effect of a 10-percent throttle step on the longitudinal parameters. Unsymmetrical throttle application affects lateral-directional control by creating a rolling moment through the dihedral effect (geometric dihedral = $7^{\circ}$ ) of the aircraft.

\section{B-720 Simulation}

A six-degree-of-freedom simulation of the B-720 aircraft was developed by interfacing the models for the aerodynamics, control systems, actuators, gear dynamics, and engines of the aircraft to a fixed-base cockpit with user interfaces. This simulation was originally used for the NASA/FAA Controlled Impact Demonstration in 1984 to further the technology for improving crash survivability onboard a transport aircraft. ${ }^{5}$ Because only limited envelope models were needed, the existing simulation primarily reflects the low-speed/low-altitude flight conditions required for the impact demonstration.

The B-720 simulation is currently interfaced with a fixedbase cockpit of a modified fighter. The cockpit provides the basic instruments necessary to operate the B-720 aircraft. A photograph of the cockpit layout appears in Fig. 3. In addition to flight instrumentation, the pilot has fingertip control of the simulation through a series of switches that enables him to hold, reset, or operate the simulation, initiate strip chart recording, vary or capture initial conditions, or select automatic trim features.

A field of general-purpose toggle switches is also provided at the cockpit and is currently used to initiate a control surface failure, enter a propulsion-only control mode, or activate the automatic landing system (ALS). Only two throttle levers were available and, as such, the inboard and outboard engines on each wing are ganged together. This grouping is not a serious limitation for the feasibility nature of the study.

A flight control system failure is simulated by bypassing the actuator model at the activation of a switch, thus locking 
the surfaces at their last position. In addition to the throttles, the pilot still has control of the flaps and the stabilizer which are electrically controlled. Separate switches are used to activate the engines-only augmented control modes in the longitudinal and lateral directions for independent study.

The simulation has dynamic "out-the-window" runway scenes displaying a $160-\mathrm{nmi}^{2}$ area of Edwards Air Force Base with its various runways (Fig. 4) on a 19-in. graphics display unit.

\section{Turbulence Model}

The B-720 simulation also includes a continuous random turbulence model that calculates turbulence velocities and angular rates ( $u, v, w, p, q$, and $r$ ). Crosswind components can also be added as a function of altitude.

\section{Aerodynamic Model}

The aerodynamic model for the B-720 aircraft is implemented based on the manufacturer's documents. The data from both wind tunnel and flight tests were reduced to support only the low altitude and Mach flight envelope.

Each aerodynamic coefficient is the sum of individual aerodynamic terms made up of nondimensional derivatives and coefficient deltas. These terms are obtained by table lookup and linear interpolation. Ground effects and the effects of c.g. position change are also modeled.

\section{Engine Model}

The B-720 aircraft uses the JT3C-7 turbojet engine. The simulation uses a modified $\mathrm{J}-57$ turbojet engine simulation model that includes control servo dynamics. The model has both table lookup functions and dynamic elements. The thrust response of the engine to a throttle command for a 160-knot, 4100-ft above sea level altitude flight condition is given in Fig. 2.

\section{Throttle-Only Transport Control}

This section discusses the general controllability issues as well as the strategies used for controlling the B-720 transport aircraft with the conventional control surfaces disabled. The discussion includes the issues from retrimming and manual throttle control to augmented and automatic control.

\section{Controllability With Flight Control Systems Failed}

With the flight control systems failed (or otherwise fixed for reasons other than electrical or mechanical trimming failures), only those systems operated electrically and mechanically are available for control of the aircraft. These electrical and mechanical systems would be req!nired to provide retrim capability for a landing attempt with throttleonly flightpath control capability. Aside from the engines, the B-720 aircraft has both the stabilizer and flaps electrically controlled. Therefore, means exist to retrim the aircraft to different flight conditions that would be required if a complete flight control system failure occurred at other than a landing configuration and flight condition. The stabilator trim rate is $0.05 \mathrm{deg} / \mathrm{sec}$ with the flaps up and $0.15 \mathrm{deg} / \mathrm{sec}$ with the flaps extended. The flap position rate is $2 \mathrm{deg} / \mathrm{sec}$.

\section{Retrimming}

A primary flight control system failure can occur anywhere in the flight envelope. Therefore, it is highly probable that the failure would occur at a trim condition that is not suitable for landing. That is, the aircraft is trimmed for a relatively high-speed flight condition. A means must be found to retrim the aircraft to an approach-type flight condition, which is generally a lower speed. Current generation aircraft have many means to accomplish this, with some aircraft having more capability than others. For example, for an aircraft with a hydraulic flight control system failure, some of the mechanisms for retrimming are: (1) electric stabilator, (2) electric flaps, (3) c.g. movement by way of electric fuel transfer or payload movement, and (4) differential thrust. (For a four-engine aircraft, a differential can be set between inboard and outboard engines to produce a pitching moment change; with a three-engine aircraft, a differential can be set between wing-mounted and centerline-mounted engines.) Typically, the trim capability of these systems is very slow even relative to throttle response characteristics; however, retrimming can be done and rate is not a key factor.

\section{Manual Throttle Control}

The primary source of pitch control is achieved through throttle-induced low-frequency speed stability effects on pitching moments. Immediate but smaller pitch axis control can be achieved through the moment arm of the aircraft c.g. to the thrust vector. Fortunately, many aircraft have engines placed on different vertical planes, thus permitting a pitching moment while holding aircraft thrust constant.

Lateral-directional control is obtained through differential throttle that produces sideslip, which in turn produces roll through the dihedral effect $C_{\ell_{\beta}}$. For aircraft with positive dihedral, the sideslip and roll motion results in conventional flying characteristics. With negative dihedral, positive sideslip would generate negative roll, resulting in a very unconventional set of control characteristics.

\section{Augmented Flight Control}

The augmented control strategy uses the stick and feedback parameters to command left- and right-engine thrust changes. The control law assumes there are ways of trimming the aircraft to an approach flight condition, as discussed earlier.

Longitudinal (flightpath angle command) - In the pitch axis, a flightpath angle command loop was implemented (Fig. 5). The command is designed to act primarily through the stick and has a command capability of $\pm 10^{\circ}$ of flightpath angle. In addition to flightpath angle feedback, pitch rate is also fed back to augment the damping. Although not shown on the diagram, moving the throttles symmetrically 
forward (aft) results in an increase (decrease) in flightpath angle which is equivalent to a positive (negative) stick input flightpath angle command. The transient response to a step flightpath angle command is shown in Fig. 6.

Lateral-Directional (bank angle command) - A lateraldirectional flightpath control law was implemented (Fig. 7) using lateral stick displacements to command bank angle. The damping of the augmented dutch roll mode is very light despite roll rate and sideslip feedback. However, the mean bank angle holds well if care is taken not to excite the dutch roll. The transient response to a step bank angle command is shown in Fig. 8. A quick look at lateral stick commanding only differential throttle (without any feedback) was also conducted. In this case, the dutch roll damping problem is significantly reduced. However, there is a spiral instability to manually control.

\section{Automatic Landing System}

A simplified ALS was designed and implemented to examine its usefulness for emergency, throttle-only flightpath control. The ALS consisted of adding outer loops to the augmented control laws and driving the lateral offset angle to zero to fly a desired flightpath angle. A model of an ALS guidance system was used to produce directional course and glide slope error signals that guided the aircraft to an unassisted landing on the runway. The A.LS guidance model consisted of a localizer and glide slope model, which provided directional course information and glide slope error, respectively. The localizer transmitter was positioned $14,000 \mathrm{ft}$ past the threshold and the glide slope transmitter was positioned at the desired touchdown point, $1000 \mathrm{ft}$ past the threshold. The glide slope angle could be varied but was set at $2^{\circ}$ for automatic landing tests. This setting reflects the desire for a reduced rate of sink for the degraded mode of operation. The ALS control laws are given in Fig. 9.

The ALS algorithm was separated into three precomputed phases. During the first phase, which started with the engagement of the ALS, the aircraft converged onto the runway centerline and commanded glide slope angle. The aircraft then transitioned at a 1000 -ft altitude above the ground to phase 2. This phase consisted of an approach to the runway at a fixed sink rate while staying aligned with the runway centerline. The final phase was the same as the second phase, except for a flare commanded at $200 \mathrm{ft}$ above ground level.

Though a simplified approach was used to demonstrate an autoland system, the algorithm derived was satisfactory to demonstrate the feasibility of such a mode.

\section{Flying Qualities Evaluations}

Four NASA transport-qualified research pilots participated in the flying qualities evaluation for both the clean cruise and the approach and landing configuration tasks. Pi- lot comments and ratings based on the Cooper-Harper scale ${ }^{4}$ were used to evaluate the propulsion-only control strategies. The evaluations cover manual throttle control and augmented flightpath control. Pilot evaluations were not made for the automatic landing mode.

\section{Maneuvers and Tasks}

Selected time histories of the simulation responses for the various flying tasks are given with the results and discussion. In each case, the pilot flew the aircraft using only throttle modulation, called manual mode, and also with the throttle augmentation control laws, called augmented mode. Although all the tasks involved six-degreesof-freedom, the longitudinal and lateral-directional modes were rated separately.

These tasks were flown with various levels of turbulence available through the simulation. Evaluations were conducted for no, light, and moderate turbulence levels as specified in MIL-F-8785. ${ }^{6}$ Because of the difficulty involved in flying the manual mode task, the no turbulence level case was included to evaluate a best case situation. The light turbulence level primarily served the function of giving the pilot a somewhat realistic task. The moderate turbulence level gave the pilots an opportunity to evaluate the modes in an extremely difficult situation.

\section{General Flying Qualities}

Pilot evaluations of the handling qualities of the aircraft during cruise flight conditions and configuration were conducted. The aircraft was flown from these conditions and configuration to a landing approach flight condition and configuration. This required the pilot to maintain or change altitude, heading, and speed. These flight maneuvers were used to evaluate the handling qualities for the different flightpath control modes. Configuration changes for the B-720 aircraft were limited to stabilator changes and flap changes.

\section{Final Approach and Landing}

The pilots also evaluated the handling qualities of the aircraft during final approach and landing flight conditions. These tasks were initiated from a wings level, constant altitude flight condition of $8 \mathrm{mi}$ out at an altitude of $1800 \mathrm{ft}$ above the ground and a 1000 - $\mathrm{ft}$ lateral offset from the runway. The task was then to acquire and maintain the desired glide path and runway alignment. Two approach conditions were evaluated: the first from 160 knots in a clean configuration and the second from 145 knots with $30^{\circ}$ flaps. The first flight condition-configuration was selected as it represented the best combination identified in this limited study. The second flight condition-configuration selected represented a more typical approach and landing situation. These approach and landings were made for manual, augmented, and automatic flightpath control. 


\section{Results and Discussion}

\section{Cruise Flight Condition}

The pilot ratings for the cruise flight condition are summarized in Fig. 10. The manual mode configuration was evaluated with no, light, and moderate turbulence levels. For the no and light turbulence levels, the pilot ratings (PR) averaged 8 with only a slight degradation resulting in light turbulence. The results indicate general maneuvering can be accomplished but with great difficulty. At the moderate turbulence level, control is usually lost at some point, thus resulting in $\mathrm{PR} \approx 10$.

The throttle augmentation mode significantly improves the pilots' ability to control flightpath. For light turbulence, the longitudinal pilot evaluations were quite good with the average rating at approximately $\mathrm{PR} \approx 3.5$. There was a 2-PR drop in ratings for the moderate turbulence level. The lateral-directional ratings were usually 1 PR rating less desirable than for longitudinal. The lower lateral-directional ratings are because of the poor dutch roll characteristics of the closed-loop bank angle command loop.

The spread of the data is more than would normally be observed in a well-conducted handling qualities evaluation. The throttle-only control system cannot be flown like a conventional control system. Using only throttles as the flightpath controller is significantly different than conventional flightpath control. This resulted in a wide variation in the pilots' ability to adapt to the new system. Another factor is the poor dutch roll damping of the basic B-720 aircraft. The low-frequency response characteristics require a significantly different piloting technique. The technique that appears most successful is one of making small commands, observing the resulting quasi-steady effects, and then repeating the process. Pilots using this technique performed well and were more favorable in their comments. This technique is not difficult and is readily learned by most pilots. Pilots using a more conventional technique felt the aircraft response was poor, and they had difficulty performing well on the evaluation. Based on observations, the pilots with the poorer ratings could improve their technique and ratings considerably if they adopted the out-of-the-loop technique. Transitioning from conventional flying techniques to the new technique was somewhat discrete and was not a linear process. Most pilots adapted readily while others retained conventional flying techniques.

\section{Approach and Landing Flight Condition}

The pilot ratings for the $160-\mathrm{knot}$ and $0^{\circ}$ flaps approach and landing flight condition are summarized in Fig. 11. For the manual control mode under ideal conditions (with no turbulence), the landing task can be accomplished with an average rating of $P R \approx 6$. With a light level of turbulence, the task became considerably more difficult with an average rating of $\mathrm{PR} \approx 8$. As the turbulence level increased to moderate, there were three instances in eight attempts where the task could not be accomplished, which implies a $P R=10$. Even though there was extensive pilot familiarization with the manual mode before PR ratings were taken, there is a very wide spread in the results. Some pilots adapted readily to this potentially difficult task whereas others did not.

The throttle augmentation mode dramatically improves the pilots' ability to control flightpath for the approach and landing flight condition. For the light level of turbulence, the average rating was $P R \approx 3.5$, which was an improvement of approximately $4.5 \mathrm{PR}$ relative to the manual mode. As the level of turbulence increased to moderate, the pilot rating decreased by approximately 3 PR; however, the scatter is very wide. A representative time history of an approach and landing in light turbulence is shown in Fig. 12. (Note that the runway elevation is at 2300 above sea level.)

As stated before, flightpath control with the throttles is a vastly different task from conventional flight controls. Adapting to flightpath control using only throttles resulted in a wide range of piloting techniques which in turn contributed to the wide spread in the data. The data show that while some pilots adapted very well to a radically different situation, others had more difficulty. The data also clearly demonstrate the feasibility of throttle flightpath control. However, the spread of the data also indicates that additional fine-tuning of the flight control system is required, as well as comprehensive pilot training to assure the best possible aircraft-pilot performance.

The ground effect complicated the fiare for bott: manual and augmented modes because it caused a nose-down pitching moment. However, this effect did not appear to significantly affect the ratings.

The pilot ratings for the 145 -knot and $30^{\circ}$ flaps flight condition are summarized in Fig. 13. This is a more difficult task and is reflected in the significant PR drop for the manual mode flight conditions with turbulence. At this flight condition with moderate turbulence, no pilot made a successful landing. With augmentation, the average PR did not change appreciably from the 160 -knot flight condition, but the PR spread did increase slightly.

\section{Automatic Landings}

Ten automatic landing system tests were conducted for both light and moderate turbulence levels. For each turbulence level, five were done at 160 knots with $0^{\circ}$ flaps configuration, and five were done at 145 knots with $30^{\circ}$ flaps configuration. A representative time history of an approach and landing at 160 knots and $0^{\circ}$ flaps is shown in Fig. 14. Excellent performance is shown with a touchdown rate-ofsink of $9 \mathrm{fU} / \mathrm{sec}$. Further optimization of the flare algorithm could reduce this rate of sink. 


\section{Comparison of Manual, Automatic, and Automated Approach and Landings}

Landing performance measures (at the instant of touchdown) for the manual, augmented, and automatic control modes with light turbulence are shown in Fig. 15. The automatic landing control law, as expected, produces very repeatable results, and the variation in the performance measures are only a function of the random characteristics of the turbulence input. As such, the results for the automatic landing cases are summarized as shaded areas on the figure. The center of the shaded area represents the area of highest probability and decreases as the edge of the shaded area is approached. The horizontal axis is an absolute performance measure because the likelihood of being on either side of the runway centerline is equal.

Figure 15(a) gives statistics of downrange as a function of crossrange for all three modes of operation. The downrange measurement is relative to the desired aim point which is $1000 \mathrm{ft}$ past the runway threshold. The automatic mode results are very tight, with a maximum dispersion of approximately $50 \mathrm{ft}$ on either side of the centerline. The downrange dispersion is greater, ranging approximately from the aim point to $2000 \mathrm{ft}$ after the desired touchdown point. Both augmented flight conditions have results reasonably close to the automatic results. The exception was one augmented case that had a 260 -ft crossrange error. The manual flight conditions are significantly worse for all test cases.

Figure 15(b) shows statistics of sink rate as a function of bank angle for all three modes of operation. Again, the automatic mode results are very tight, with a sink rate dispersion of $\pm 3 \mathrm{fu} / \mathrm{sec}$ around a nominal $8 \mathrm{ft} / \mathrm{sec}$ rate of sink at touchdown and a bank angle dispersion of $\pm 2^{\circ}$. The augmented mode results are in the 5 - to $10-\mathrm{ft} / \mathrm{sec}$ rate-of-sink range, with a bank angle dispersion of less than $5^{\circ}$ exceeded only once. Again, there is considerably more spread with manual control, especially with the ability to control bank angle.

For moderate turbulence, the automatic landing results given along with those for both manual and augmented landing results are shown in Fig. 16 in terms of performance measures at the instant of touchdown. The automatic mode results, as well as the augmented and the manual control results, have considerably larger dispersion areas than for the light turbulence cases.

The ground effect complicated the flare for all modes because it caused a nose-down pitching moment. In the automatic mode, the ground effect increased the rate of sink approximately $6 \mathrm{ft} / \mathrm{sec}$.

Both the augmented and automatic control laws were preliminary and only designed to demonstrate the feasibility of flightpath control using throttles only. However, even these simple control laws demonstrate that acceptable flightpath control is achievable. Note that there is little per- formance difference between the augmented and automatic modes with light turbulence.

\section{Issues Concerning Application to Other Transport Aircraft}

The preceding results apply specifically to the B-720 transport; however, similar techniques can be successfully applied to a wide range of transport configurations and probably even selected fighter configurations. The dominant issue with throttle-only flightpath control is retrimming the aircraft to realistic approach speeds. On the B-720 transport, this was accomplished by electric control of the stabilator position. This retrimming can also be accomplished to varying degrees on other aircraft by electric flap deflection, differential inboard and outboard throttle settings for four-engine transports (differential centerline and wing or body throttle settings for three-engine transports). Center of gravity control and lowering the landing gear can also assist in the retrimming task; c.g. control was not used in the B-720 study.

Because both the pitch and roll axes are controlled with the throttles, the issue of axis hierarchy comes into play when throttle authority limits are reached. This problem is in many ways similar to the pitch and roll axis mixing for aircraft with elevons.

In this study, the pilot's stick was used for pitch and roll control in a conventional fashion. However, some pilot comments show that because piloting techniques are so different, there should be a kind of side panel control operating similar to autopilot commands. This type of control would also avoid the problem of the pilot relapsing into conventional piloting techniques in a high workload situation.

The control laws given in this paper could not be readily implemented in the majority of transport aircraft flying today with the exception of fully digital fly-by-wire aircraft. The technology should be considered as an additional methodology in addressing flightpath control redundancy issues. Future generation aircraft will be fully digital flyby-wire. Thus, incorporation of the discussed technology will represent a small portion of the overall control system design effort.

These issues, as well as others, must be addressed by follow-on simulation and flight test studies before attempting a flight test demonstration of throttle-only flightpath control.

\section{Concluding Remarks}

The use of throttle control laws in the event of a total loss of conventional fight control surfaces was evaluated. The final results are based on a fixed-base simulation evaluation, with visual display, by transport-qualified research pilots. 
The results show that throttle augmentation control laws can provide the flightpath control capability to land a transport-type aircraft with up to moderate levels of turbulence. The throttle augmentation mode dramatically improves the pilots' ability to control flightpath for the approach and landing flight condition. For the light level of turbulence, the average Cooper-Harper pilot rating improved by 4.5 in going from manual to augmented control. The flightpath control technique is different because of the low frequency response characteristics of the engines. Also, the various techniques used by the pilots resulted in considerable scatter in the data. Many pilots readily learned a good piloting technique while some had difficulty. Although a good piloting technique is different than conventional flightpath control, it was never described as either difficult to use or to learn.

A new and viable approach was shown for providing an independent means of redundancy as well as for increasing the redundancy capability of transport aircraft flightpath control.

\section{References}

1 "Inquiry Committee Analyzes JAL 747 Flight Data Recorder," Aviation Week \& Space Technology, vol. 123, no. 10 , Sept. 9,1985, p. 97.
2 "United DC-10 Crashes in Sioux City, Iowa," Aviation Week \& Space Technology, vol. 131, no. 4, July 24, 1989 , pp. 96-97.

${ }^{3}$ Burcham, F.W., Fullerton, C. Gordon, Gilyard, Glenn B., Wolf, Thomas D., and Stewart, James F., "A Preliminary Investigation of the Use of Throttles for Emergency Flight Control," AIAA 91-2222, June 1991.

${ }^{4}$ Harper, Robert P., Jr., and Cooper, George E., "A Revised Pilot Rating Scale for the Evaluation of Handling Qualities," AGARD CP 17, Stability and Control-Part 1, Sept. 1966.

${ }^{5}$ Horton, Timothy W., and Kempel, Robert W., Flight Test Experience and Controlled Impact of a Remotely Piloted Jet Transport Aircraft, NASA TM-4084, 1988.

${ }^{6}$ MIL-F-8785B(ASG), Flying Qualities of Piloted Airplanes, Military Specification, U.S. Air Force, Aug. 7, 1969. Available from Wright-Patterson Air Force Base, Ohio. 


\section{ORIGINAL PAGE \\ BIACK AND WHITE HHOTOGRAPH}

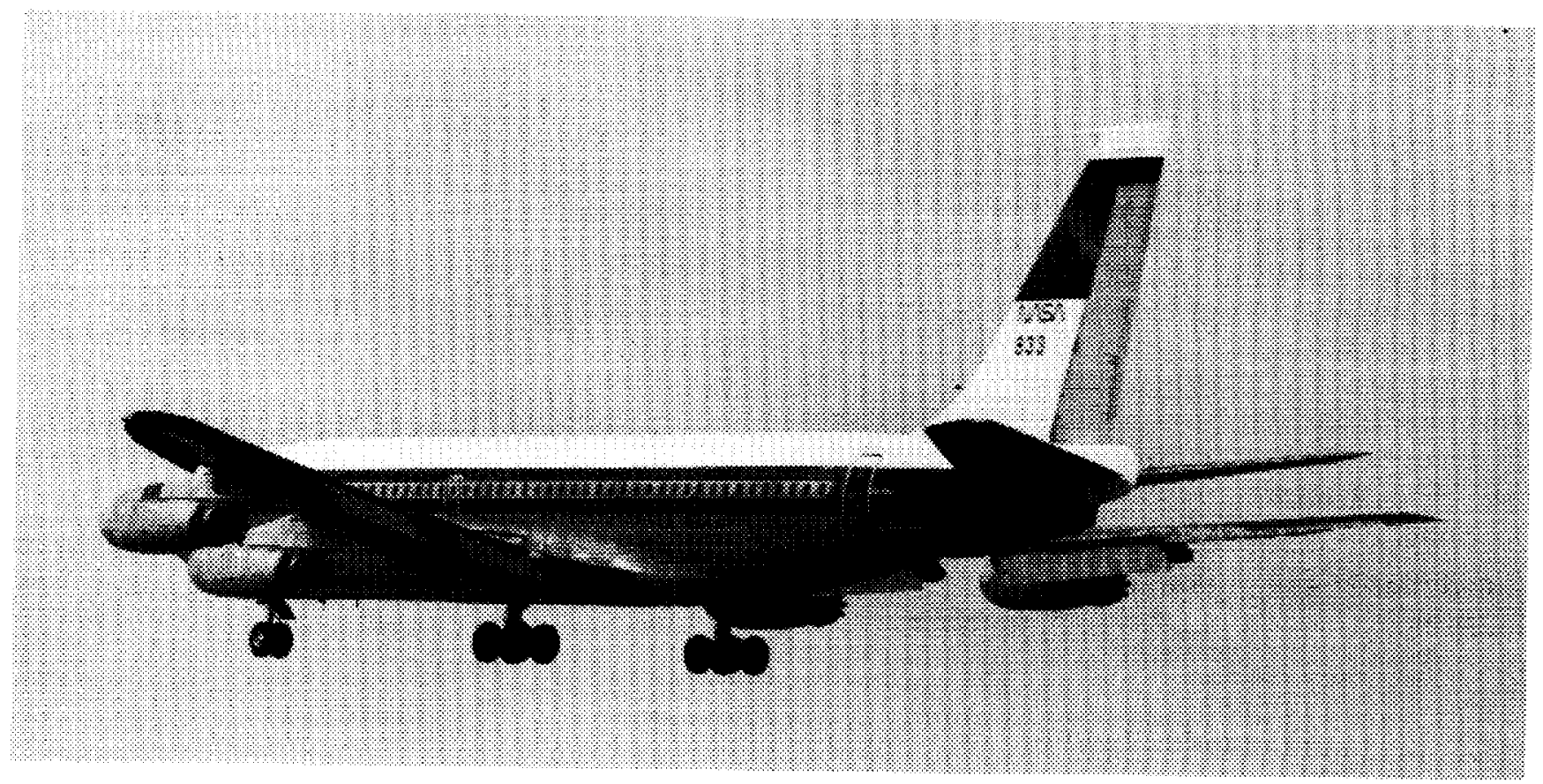

(a) Landing gear and flaps down.

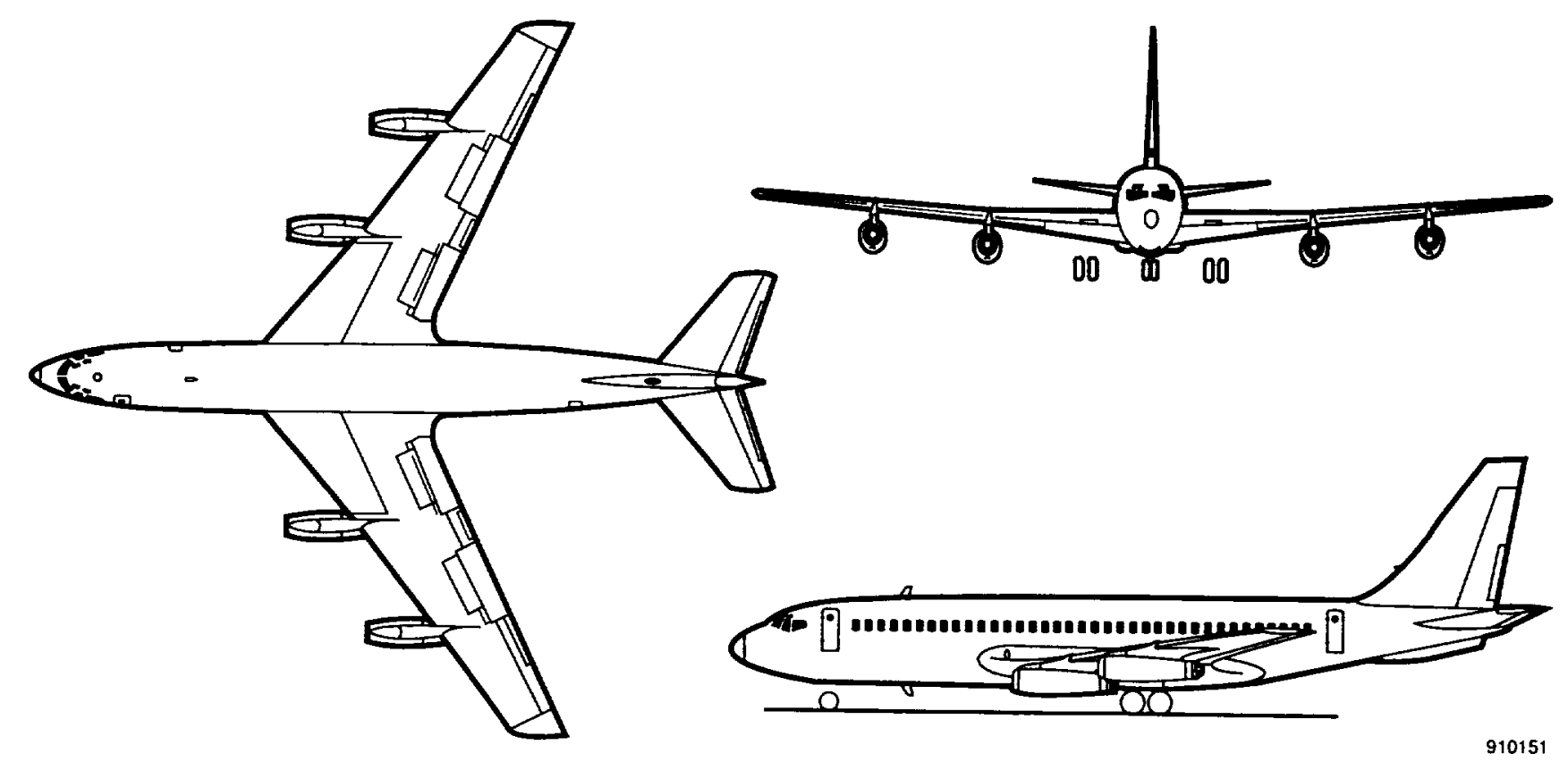

(b) Three-view.

Fig. 1 B-720 test aircraft. 


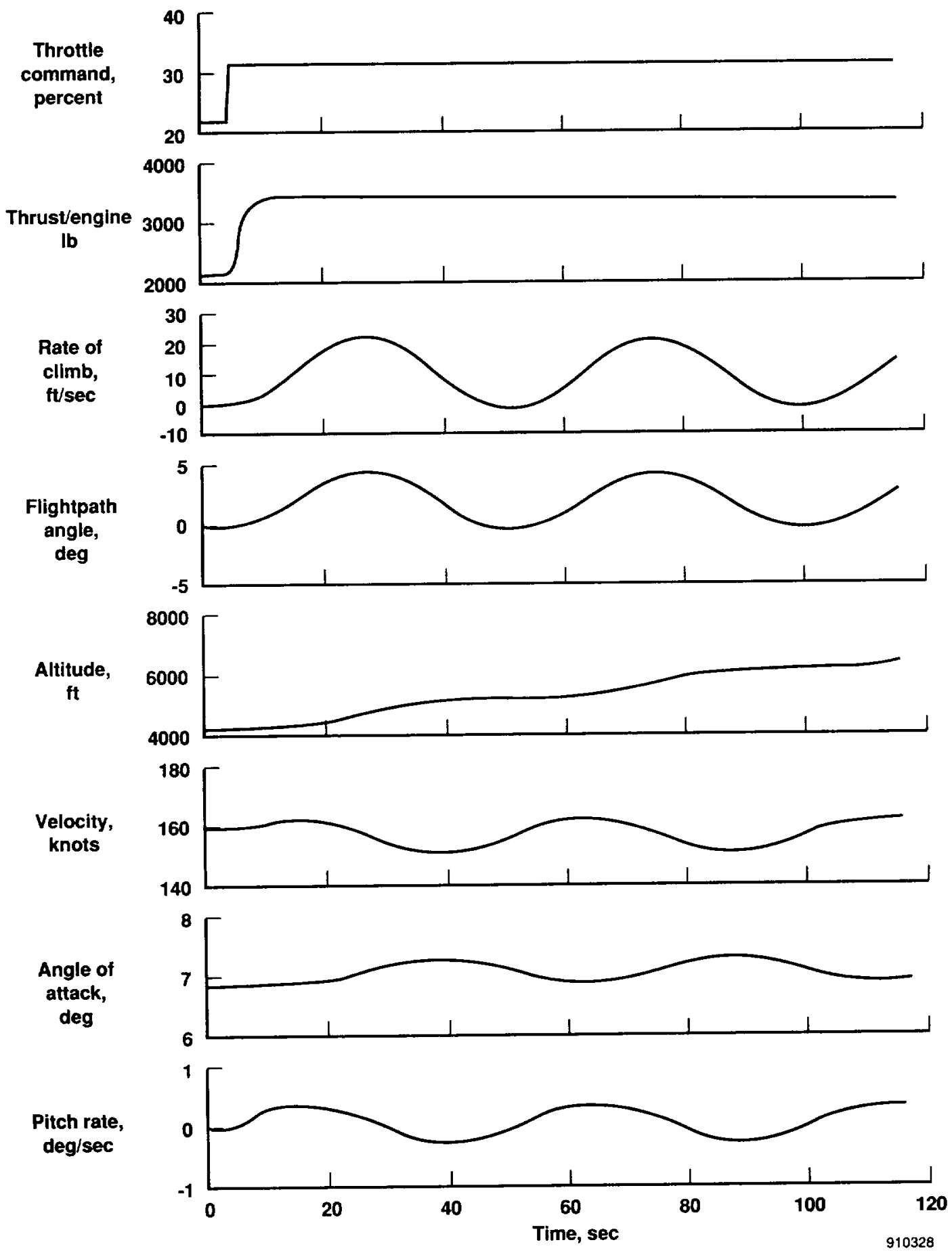

Fig. 2 B-720 step throttle response; 160 knots, $0^{\circ}$ flaps, approach condition. 
OAIOINAI, FERE

DACK ANO WHITE FHOTOGRAPH

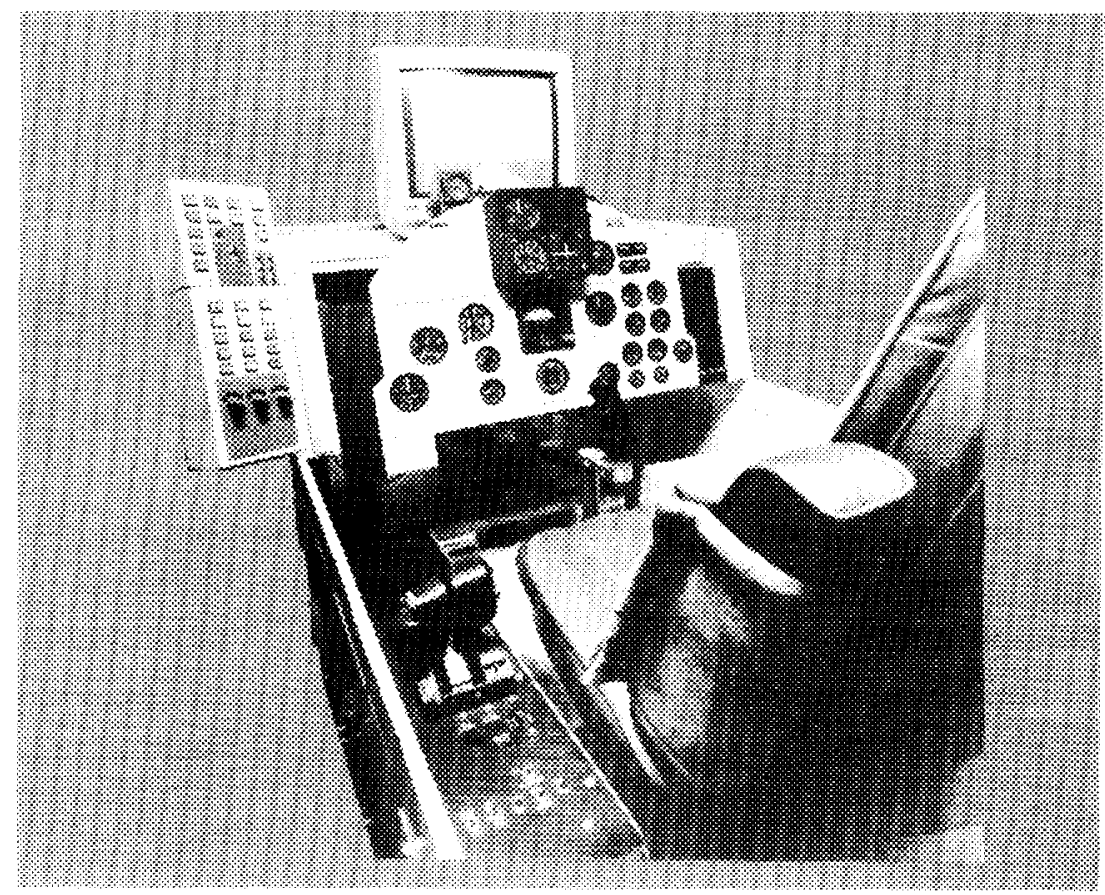

EC $90-227-1$

Fig. 3 Simulation cockpit used for B-720 throttle control study.

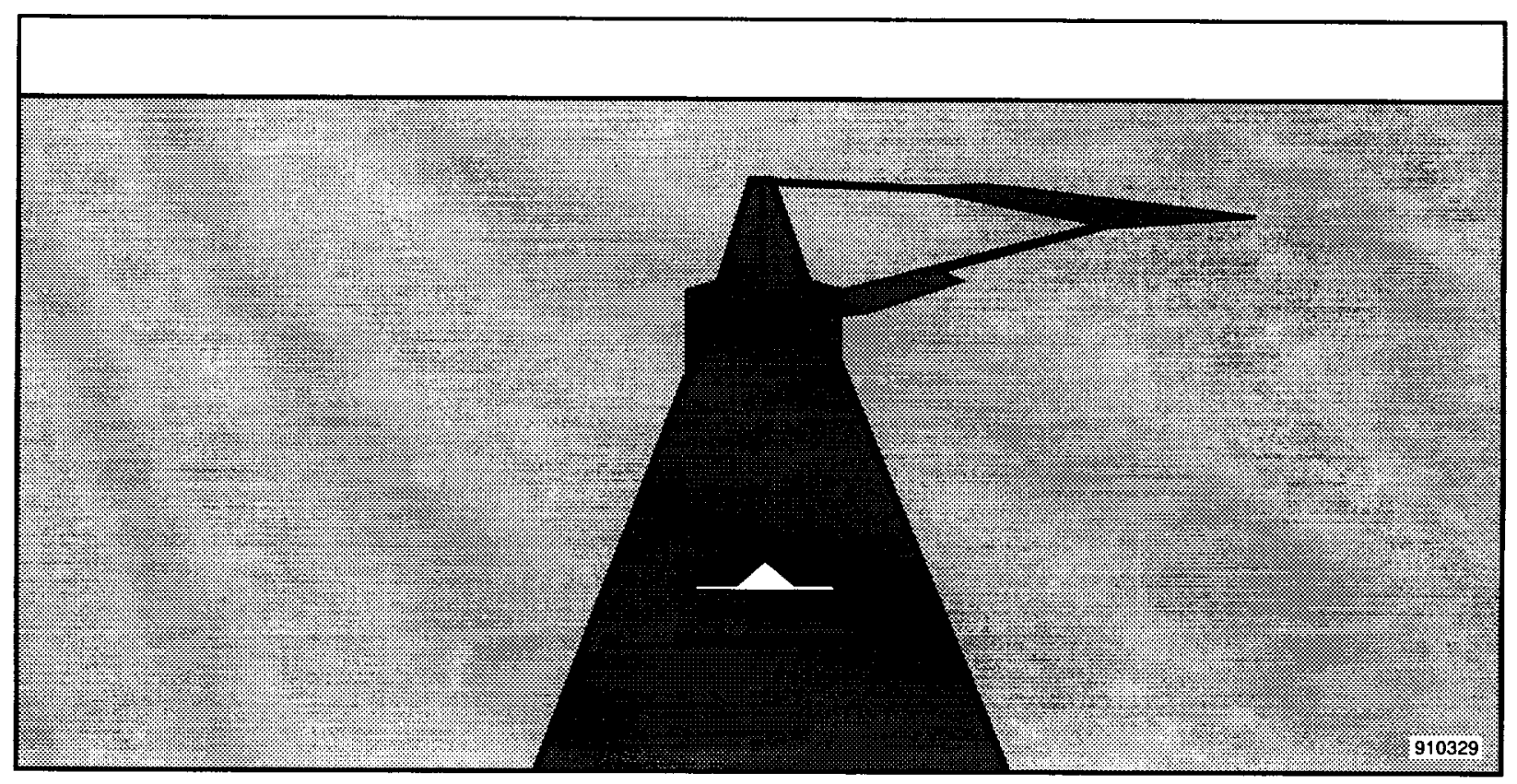

Fig. 4 Approach and landing visual display. 


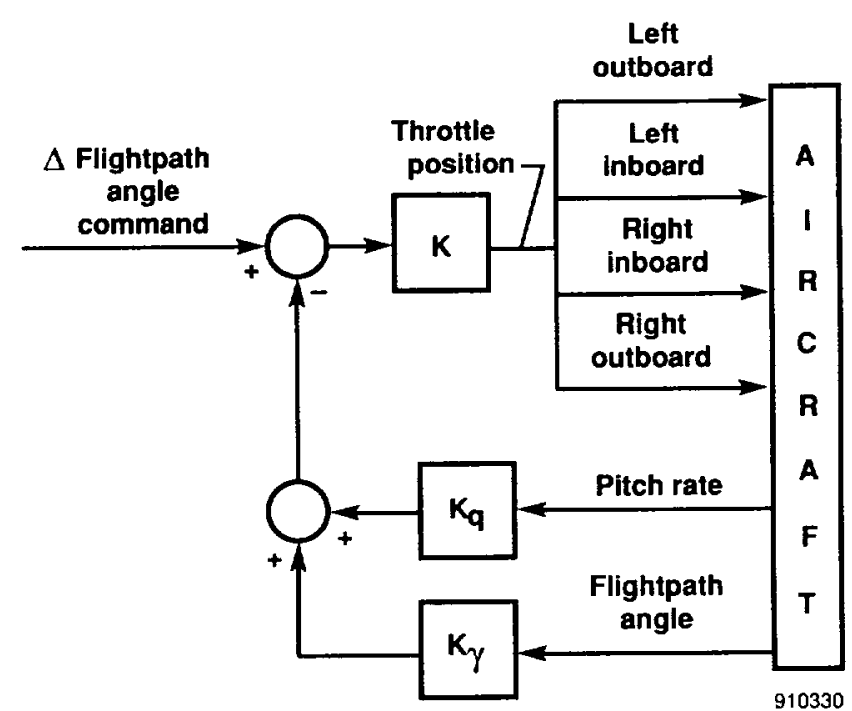

Fig. 5 Longitudinal block diagram; flightpath angle control.

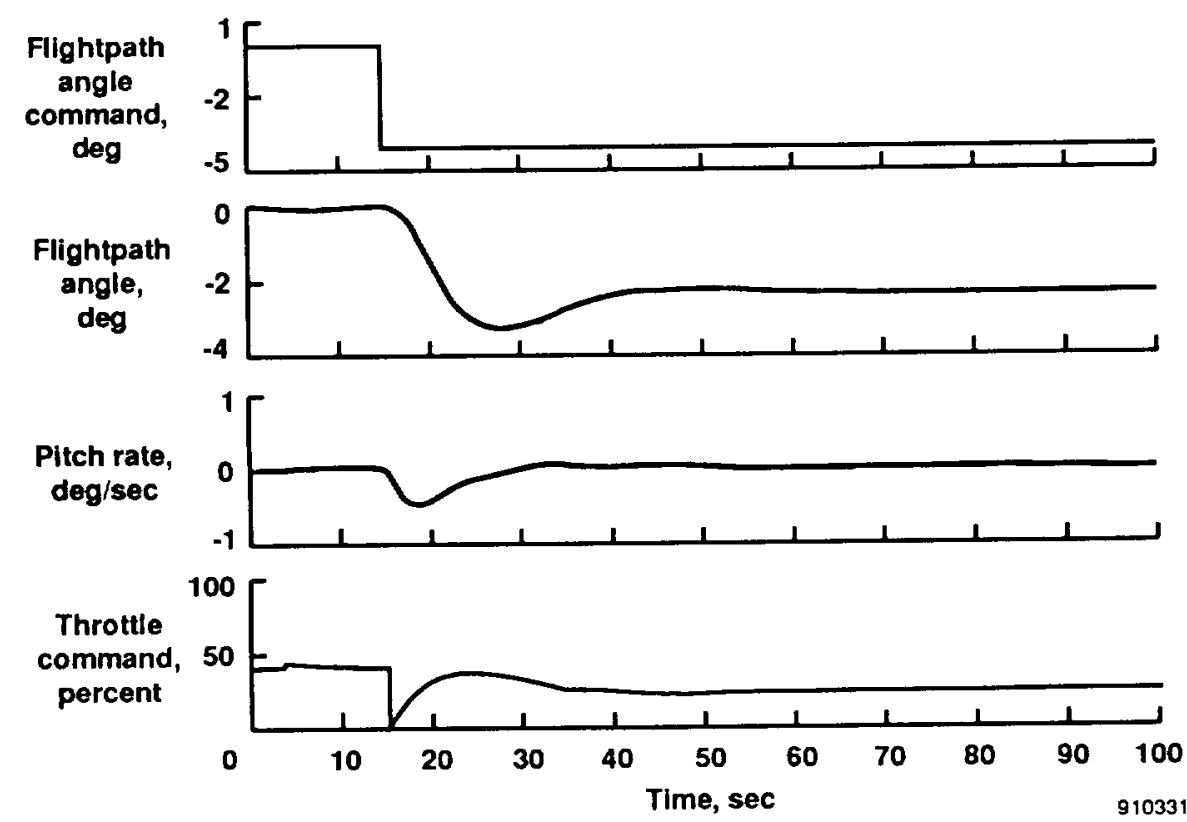

Fig. 6 Flightpath angle step response; 160 knots, $0^{\circ}$ flaps, approach condition. 


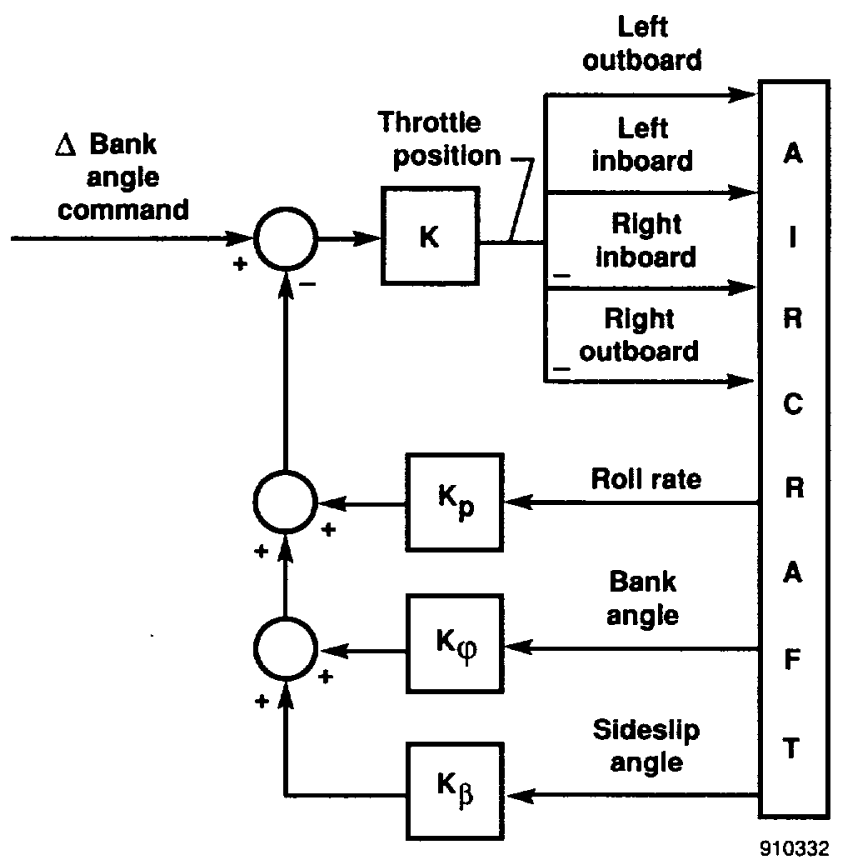

Fig. 7 Lateral-directional block diagram; bank angle and heading control.

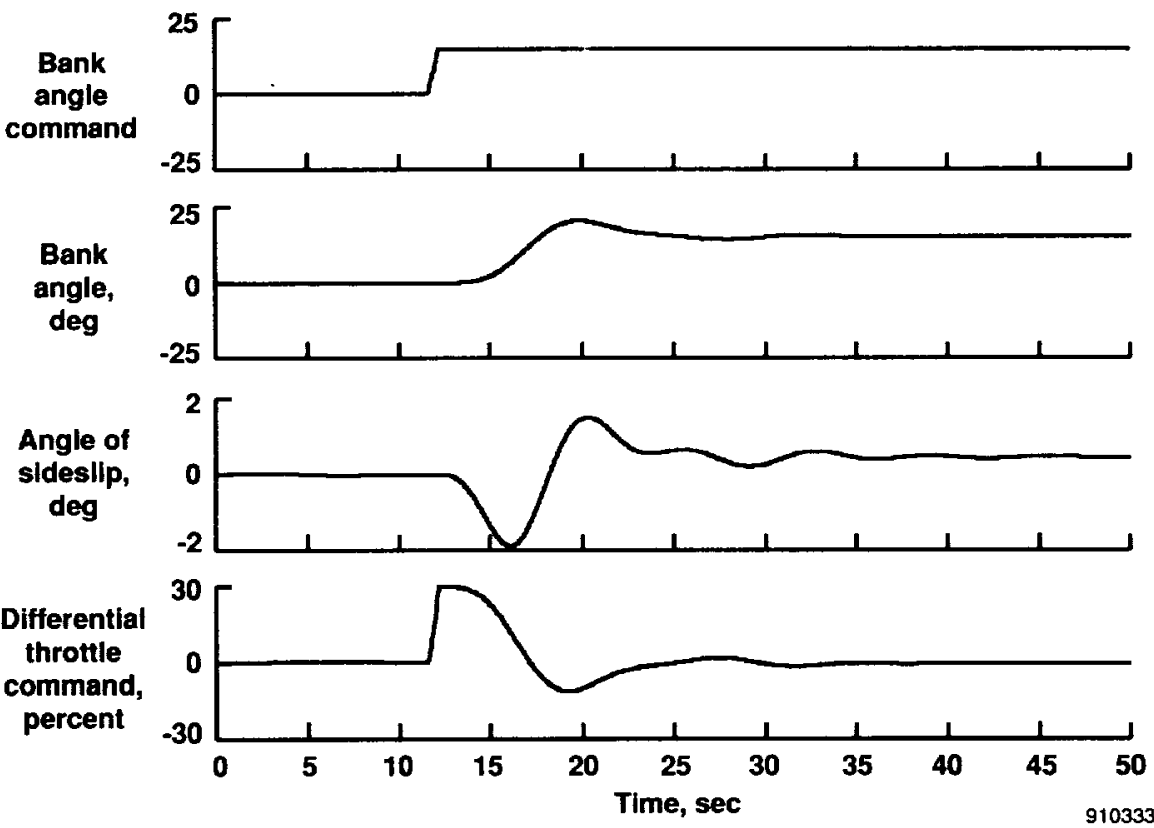

Fig. 8 Bank angle step response; 160 knots, $0^{\circ}$ flaps, approach condition. 


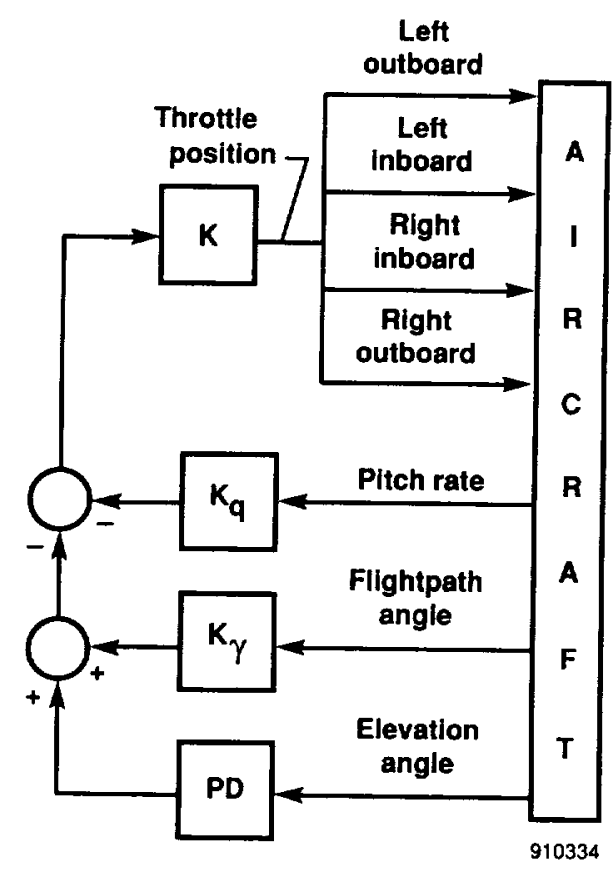

(a) Longitudinal.

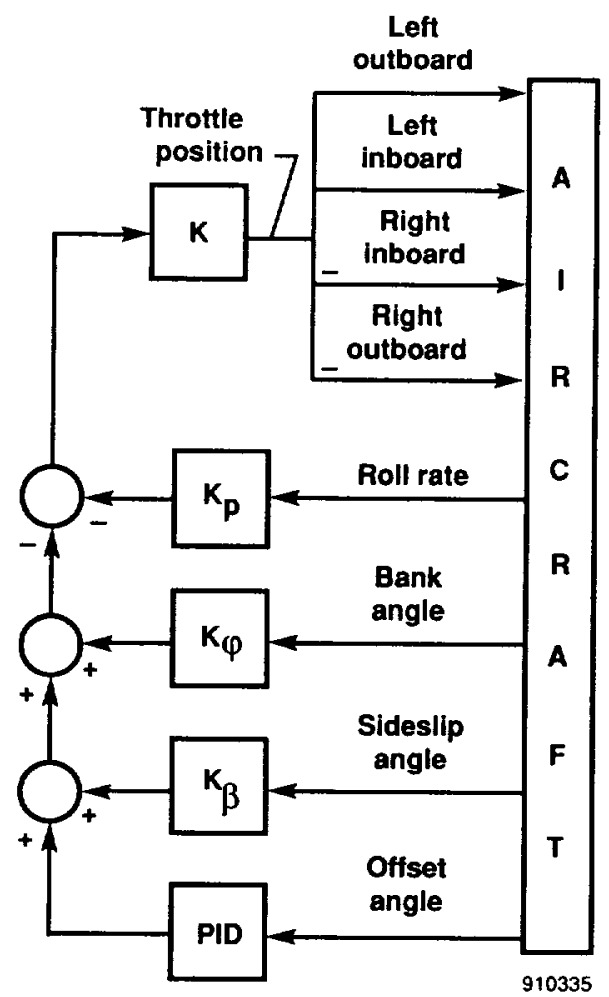

(b) Lateral-directional.

Fig. 9 Automatic landing system block diagram. 


\section{Cruise}

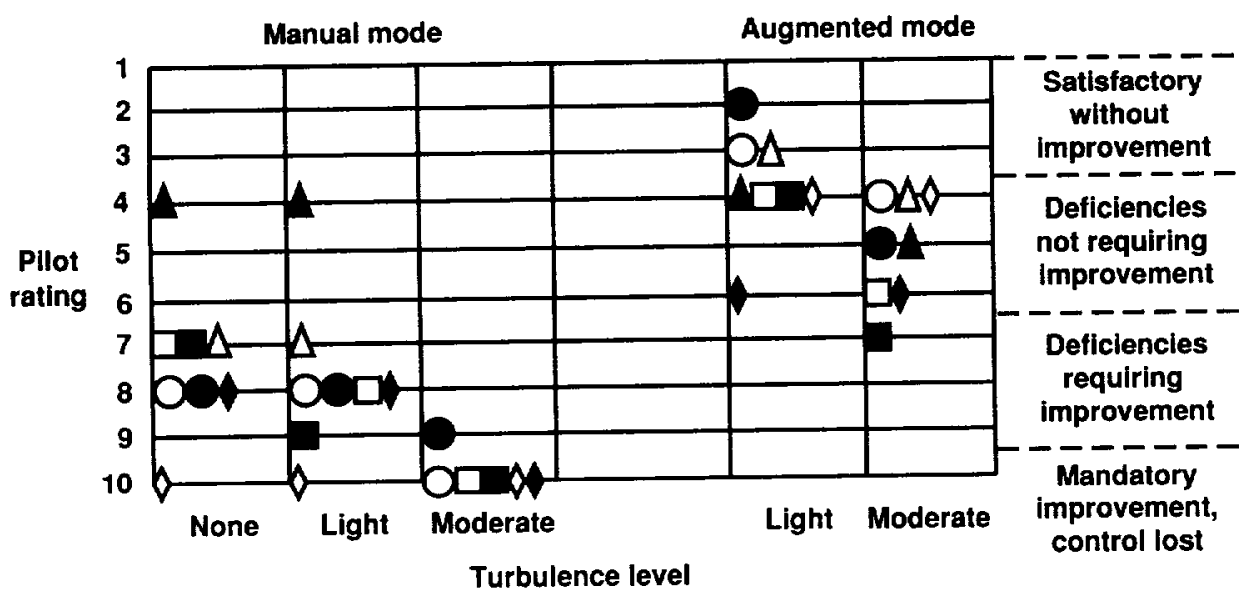

LateralLongitudinal directional

$\begin{array}{ll}0 & 0 \\ \square & \\ \Delta & \end{array}$

Pilot 1

Pilot 2

Pilot 3

Pilot 4

910336

Fig. 10 Cooper-Harper pilot ratings for manual and augmented modes at different turbulence levels; cruise handling quality results.

\section{Landing at 160 knots, $0^{\circ}$ flaps}

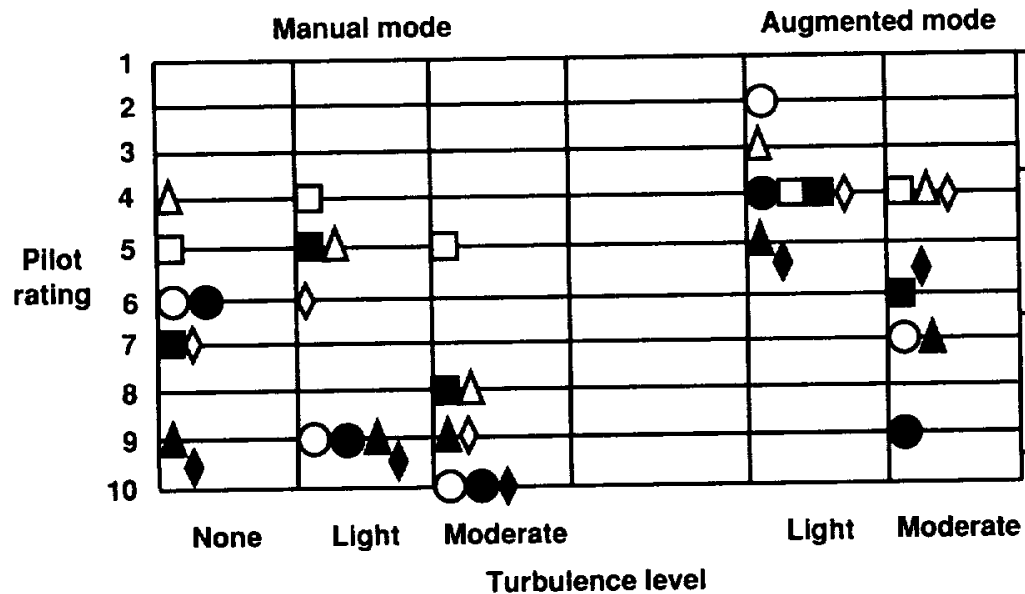

LateralLongitudinal directional Satisfactory without improvement

Deficiencies not requiring improvement

$\begin{array}{ll}0 & 0 \\ \Delta & \square\end{array}$

Pllot 1

Pilot 2

Pllot 3

$------$

Deficiencies requiring improvement

Mandatory Improvement, control lost

Pilot 4

Fig. 11 Cooper-Harper pilot ratings for manual and augmented modes at different turbulence levels; approach and landing handling quality results. 

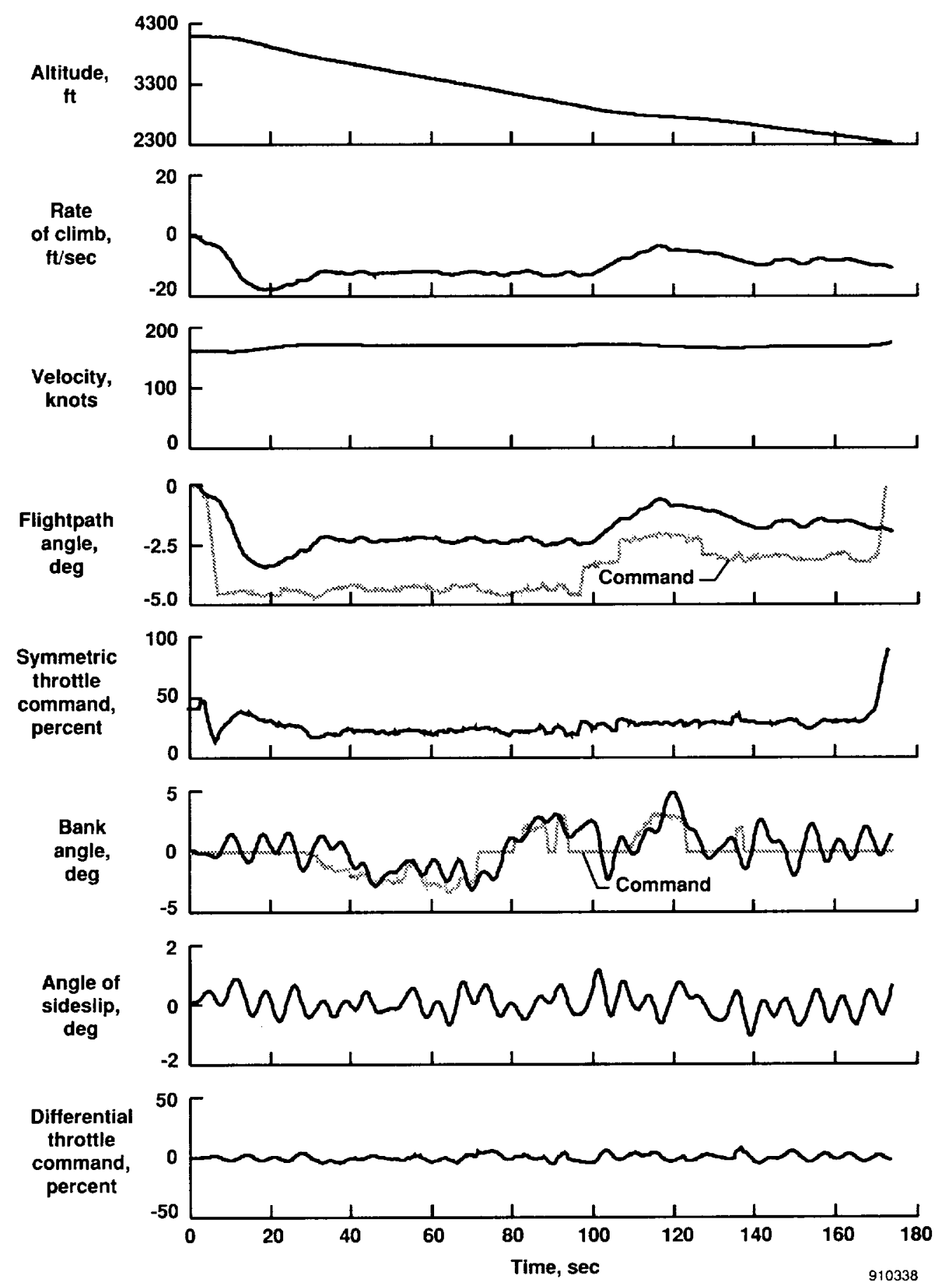

Fig. 12 Time history of augmented approach and landing; 160 knots, $0^{\circ}$ flaps, light turbulence, $1000-\mathrm{ft}$ offset. 


\section{Landing at 145 knots, $30^{\circ}$ flaps}

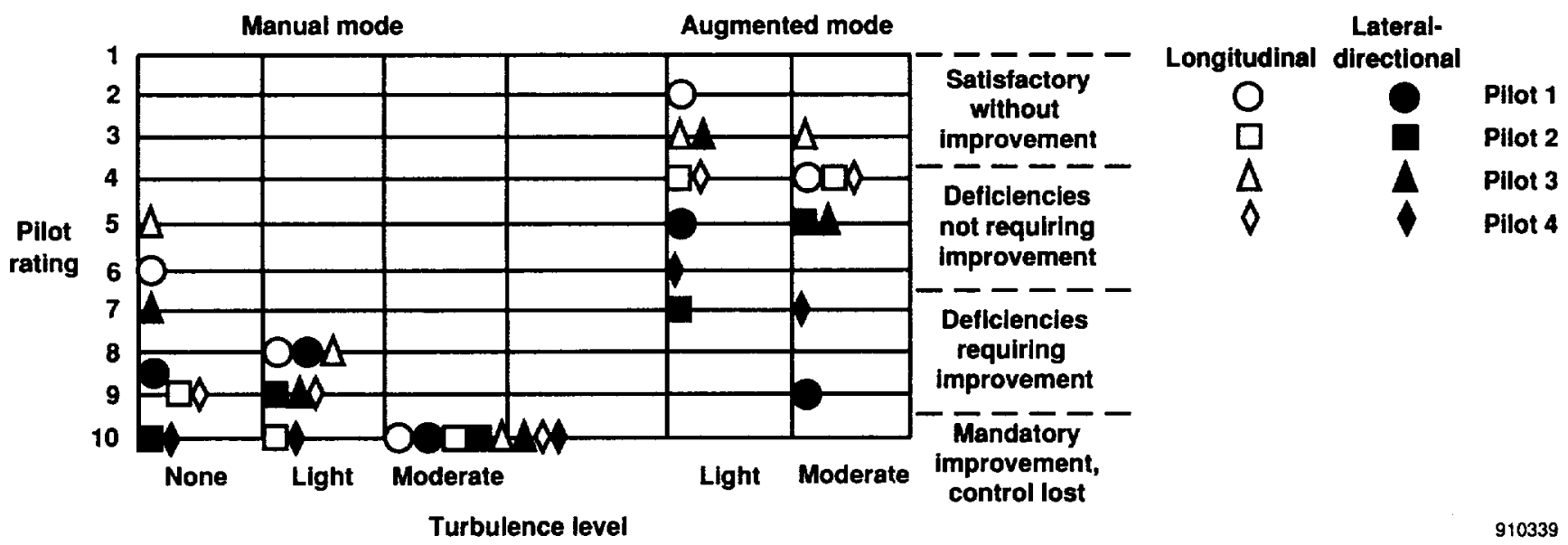

Fig. 13 Cooper-Harper pilot ratings for manual and augmented modes at different turbulence levels; approach and landing handling quality results. 


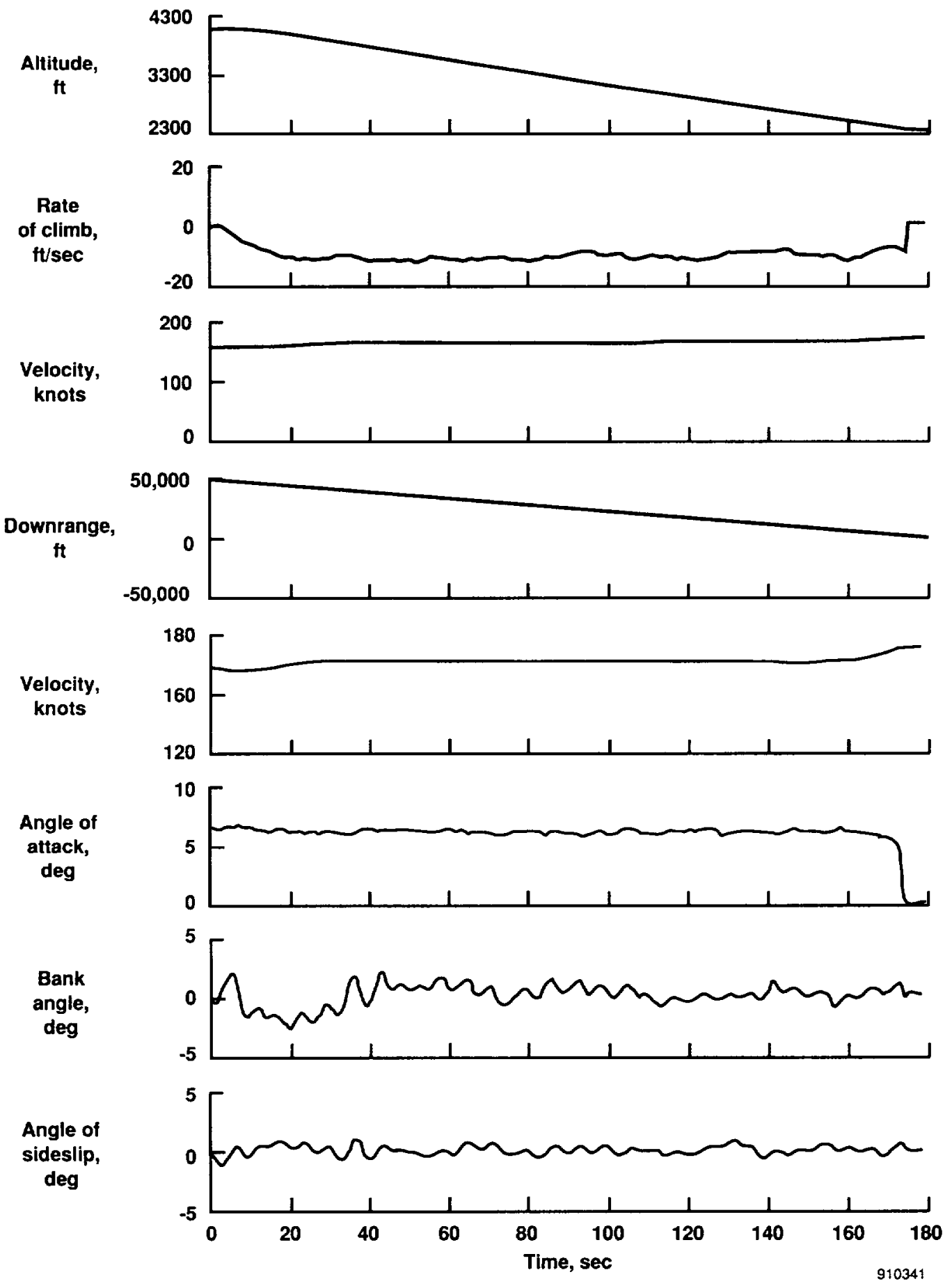

Fig. 14 Time history of automated approach and landing; 160 knots, $0^{\circ}$ flaps, light turbulence, 1000 -ft offset. 


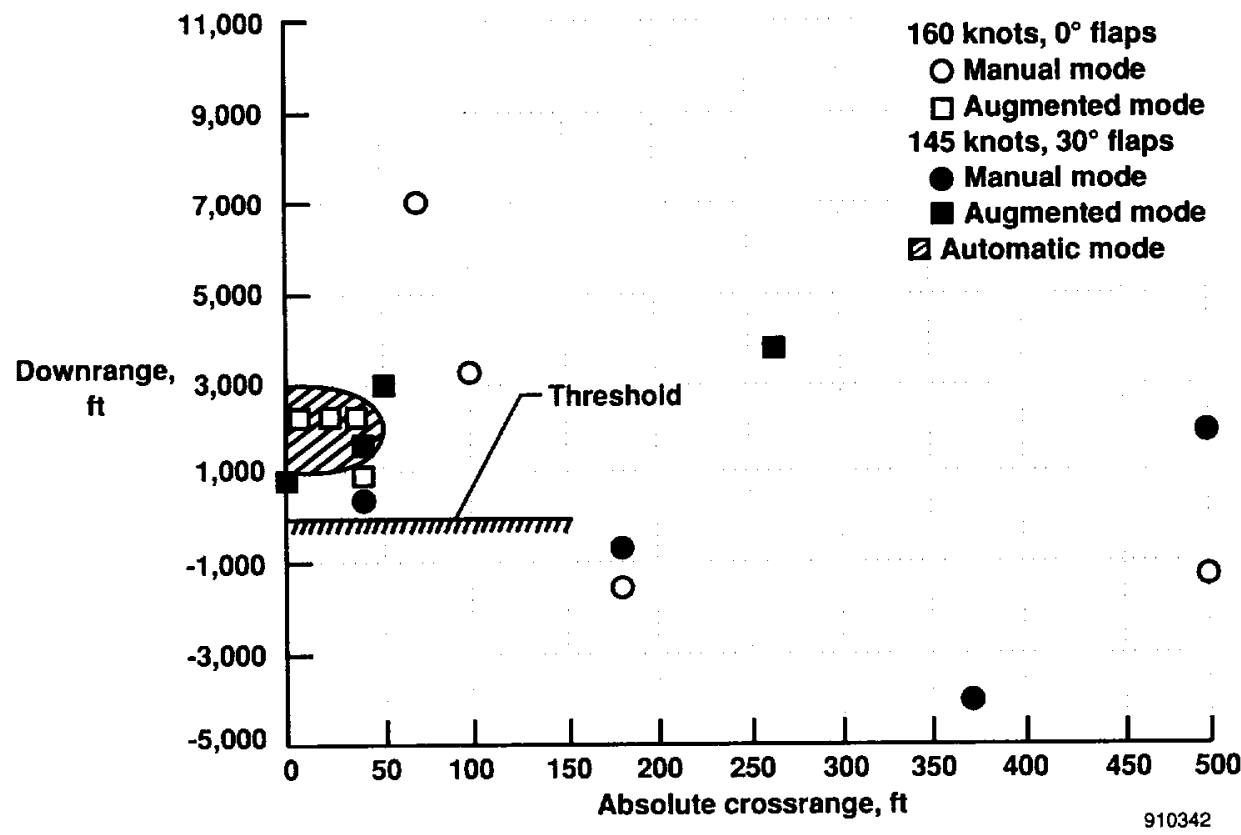

(a) Downrange as a function of crossrange.

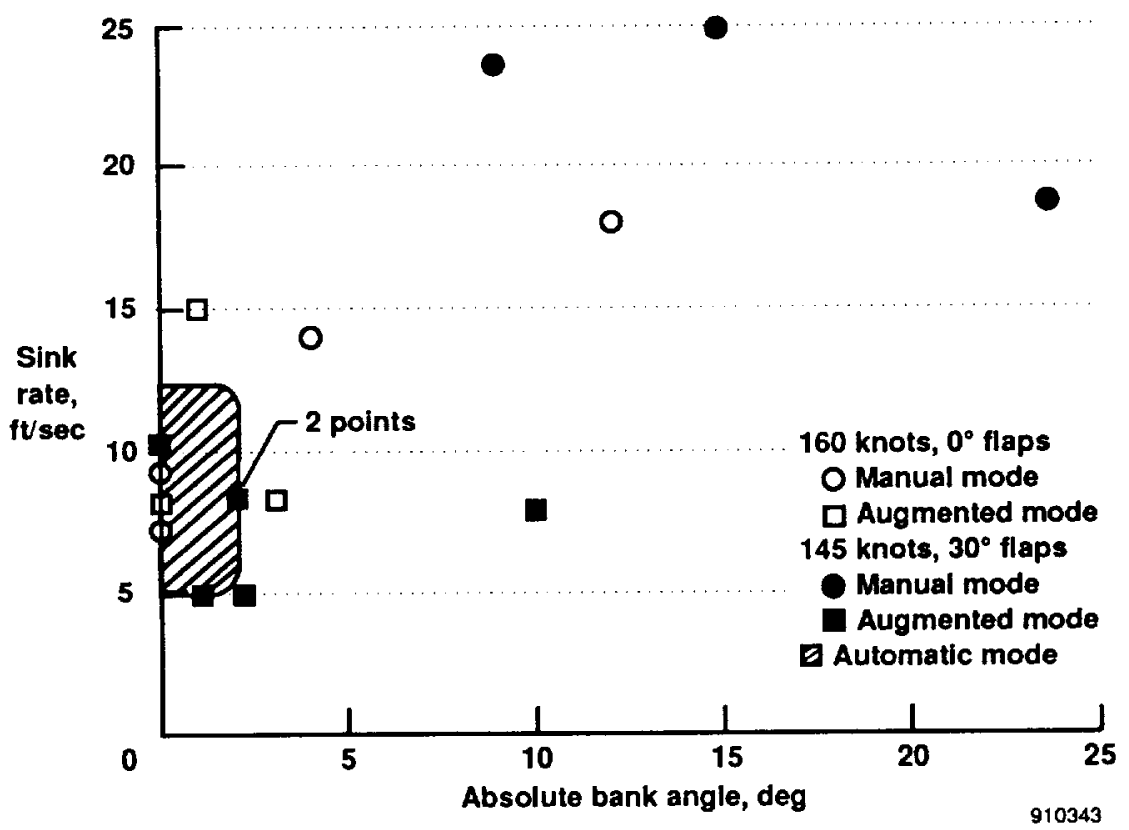

(b) Rate-of-sink as a function of bank angle.

Fig. 15 Landing performance measures, light turbulence. 


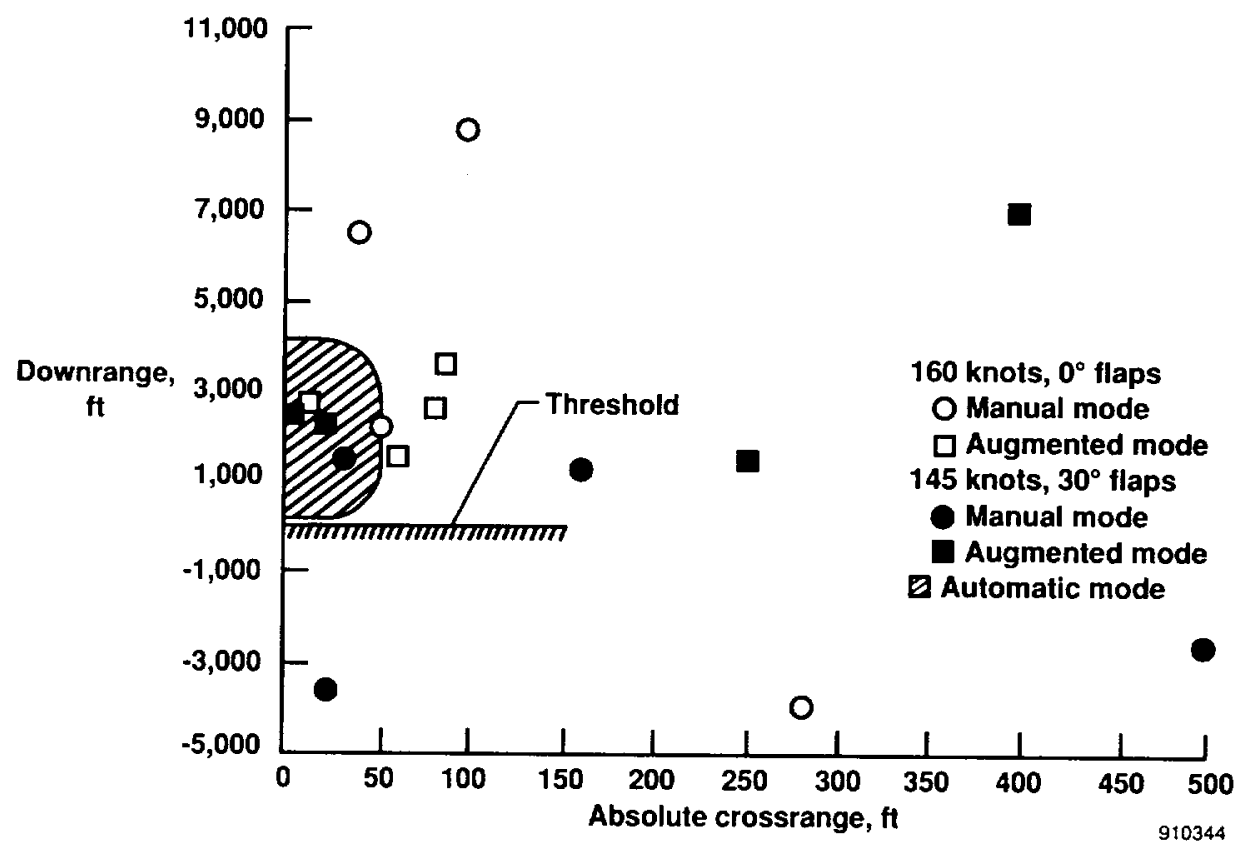

(a) Downrange as a function of crossrange.

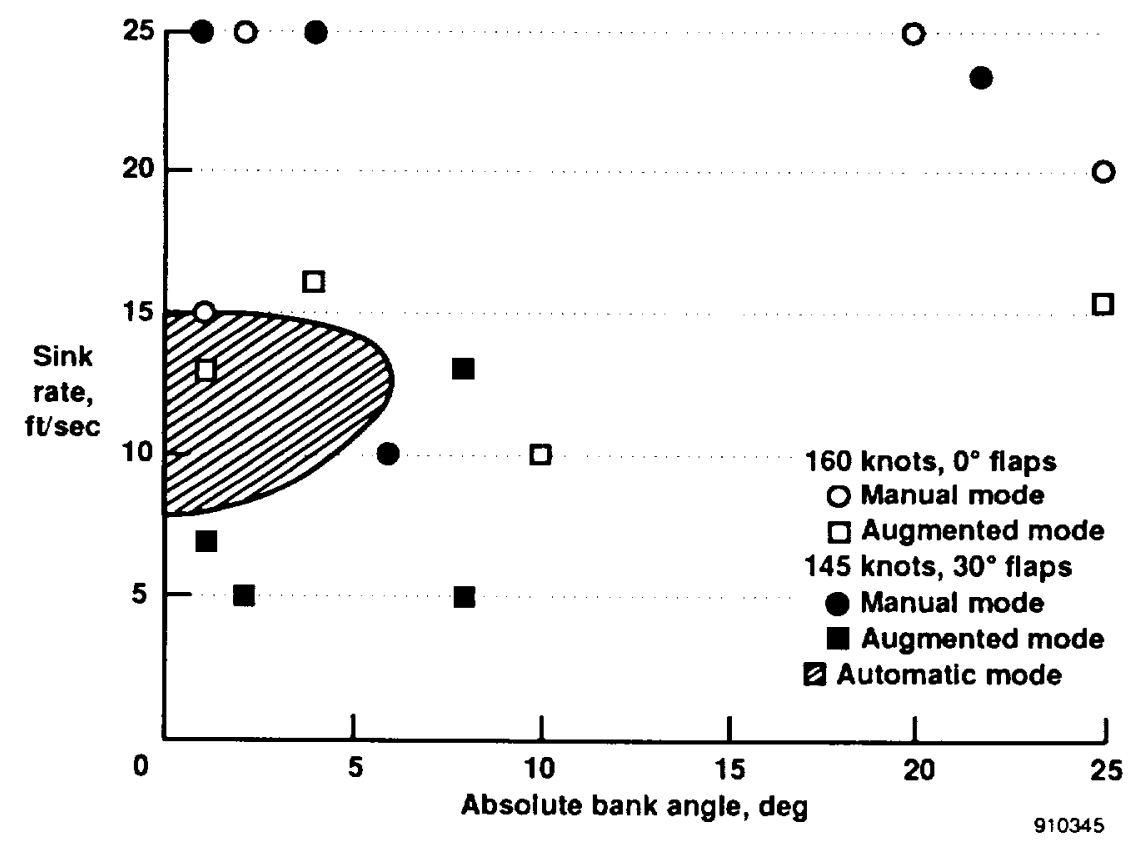

(b) Rate-of-sink as a function of bank angle.

Fig. 16 Landing performance measures, moderate turbulence. 




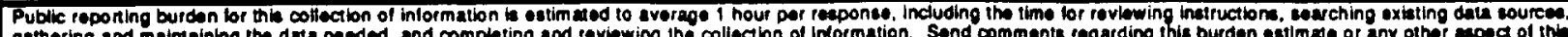

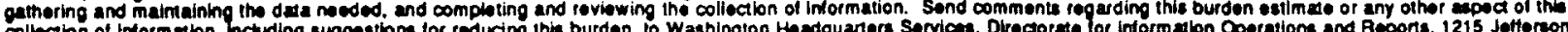

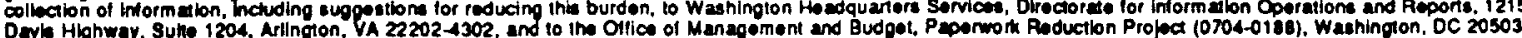
1. AGENCY USE ONLY (Leave blenk)
2. REPORT DATE
September 1991
3. AEPORT TYPE AND DATES COVERED
Technical Memorandum

4. TITLE AMD SUBTITLE

5. FUNDING NUMBERS

A Simulation Evaluation of a Four-Engine Jet Transport Using Engine

Thrust Modulation for Flightpath Control

6. AUTHOA(S)

WU-505-64

Glenn B. Gilyard, Joseph L. Conley, Jeanette Le, and

Frank W. Burcham, Jr.

7. Performing organization mame(S) ano adoress(ES)

8. PERFORMINO ORGANIZATION

REPORT NUMBER

NASA Dryden Flight Research Facility

P.O. Box 273

$\mathrm{H}-1741$

Edwards, Califomia 93523-0273

9. SPONSORING/MONITORINO AGENCY NAME(S) AND ADDRESS(ES)

SPONSORINO/MONITORINC

AOENCY REPORT NUMBEA

National Aeronautics and Space Administration

Washington, DC 20546-0001

NASA TM- 4324

11. SUPPLEMENTARY NOTES

Prepared for the AIAA/ASME/SAE/ASEE 27th Joint Propulsion Conference, Sacramento, California, June 24-26, 1991.

12. DISTRIQUTION/AVAILABILITY STATEMENT

12b. DISTRIBUTION CODE

Unclassified - Unlimited

Subject Category 08

\section{AESTRACT (Maxlmum 200 mords)}

The use of throttle control laws to provide adequate flying qualities for flightpath control in the event of a total loss of conventional flight control surface use was evaluated. The results are based on a simulation evaluation by transport research pilots of a B-720 transport with visual display. Throttle augmentation control laws can provide flightpath control capable of landing a transpont-type aircraft with up to moderate levels of turbulence. The throttle augmentation mode dramatically improves the pilots' ability to control flightpath for the approach and landing flight condition using only throttle modulation. For light turbulence, the average Cooper-Harper pilot rating improved from unacceptable to acceptable (a pilot rating improvement of 4.5 ) in going from manual to augmented control. The low frequency response characteristics of the engines require a considerably different piloting technique. The various techniques used by the pilots resulted in considerable scatter in the data. Many pilots readily adapted to a good piloting technique while some had difficulty. The research demonstrates a new and viable approach to providing an independent means of redundancy or increasing the redundancy capability of transport aircraft flightpath control.

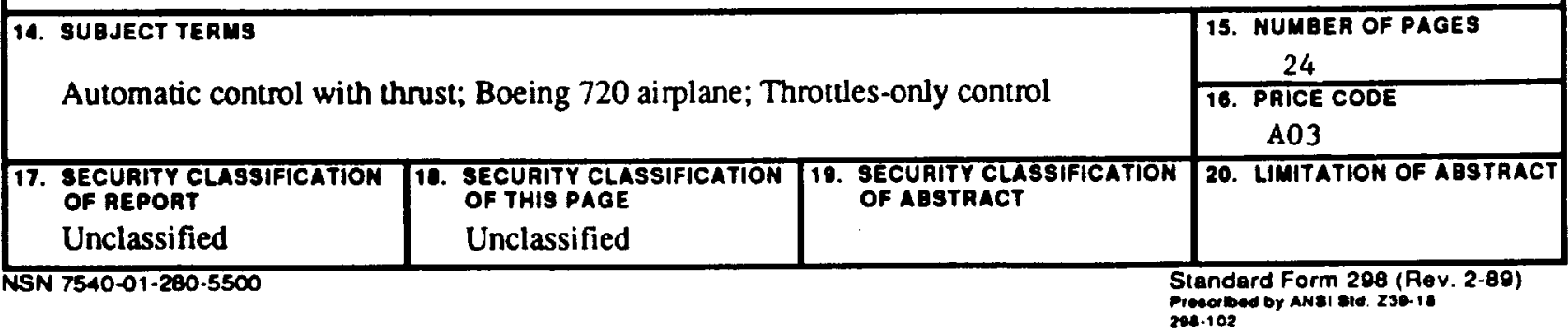

